\title{
COLUMBIA UNIVERSITY: PROJETO DE UMA MODERNIDADE CONSERVADORA
}

\author{
José Rubens Mascarenhas de Almeida ${ }^{1}$
}

\section{RESUMO}

Este artigo busca evidenciar o processo de modernização conservadora desenvolvido na América Latina da primeira metade do século XX, entendido como desenvolvido nos padrões da acumulação imperial capitalista. Tem como foco central a Bahia, resgatando o contexto nacional (Brasil) dos anos 1930-1950, marcado pelo surgimento de novos atores, novas lutas, pelas investidas conservadoramente "modernizadoras" do capital monopólico internacional e suas conexões com as classes dominantes locais. Traça as linhas mais gerais do processo de integração regional à lógica acumulativa internacional, ressaltando o papel do "Programa de Pesquisas Sociais Estado da Bahia - Columbia University", buscando resgatar a relação dialética entre as unidades e a totalidade, numa abordagem cuja perspectiva passa pela História, mais especificamente pela historia da acumulação capitalista e o que representou tal Programa no contexto em que se deu.

Palavras-chave: projeto Colúmbia; Imperial capitalismo; Modernização conservadora.

\section{COLUMBIA UNIVERSITY: PROJECT OF A CONSERVATIVE MODERNITY}

\begin{abstract}
This article seeks to show the process of conservative modernization in Latin America developed the first half of the twentieth century, as understood in developed patterns of imperialist capital accumulation. Its central focus is Bahia, rescuing the national context (Brazil) the years 1930-1950, marked by the emergence of new actors, new struggles, conservatively invested by "modernizing" the international monopoly capital and its connections with the local ruling classes. Traces the lines of the more general process of regional integration logic accumulative international, emphasizing the role of the "Program for Social Research State of Bahia - Columbia University", seeking to rescue the dialectical relationship between the units and the whole, an approach whose perspective goes through History more specifically the history of capitalist accumulation and representing such program in the context it was given.
\end{abstract}

Keywords: Project Columbia; Imperialism; Conservative modernization.

\section{A América Latina e o imperialismo: uma modernização conservadora}

Adotamos, para enfoque deste tema, uma leitura da categoria central de análise (a de modernização conservadora) baseada na conotação mais geral advinda da abordagem do Moore Jr (1975). Em seu estudo, este sociólogo estadunidense aborda a modernização da Alemanha e do Japão na passagem do século XIX para o XX, entendendo esse processo como sendo um modelo de industrialização fundado na aliança entre a burguesia industrial, através de políticas estatais, com a oligarquia rural. Sem apelações a analogias, este é o sentido mais próximo do termo que aqui se aplica. 
Entendemos que aquilo que, na periferia sistêmica, é denominado modernização trata-se do entendimento mais geral da introdução das relações capitalistas nas áreas pretendidas pelas novas relações de produção que se instauraram com a decadência do sistema feudal. E, como todo e qualquer procedimento revolucionário que se estabeleça, ele se fundamenta em relações de profunda violência, por conta da qual se impõe novas formas de relações e métodos que atendem aos novos interesses envolvidos no procedimento. Não foi diferente no processo de inserção da América Latina no contexto do processo mais geral da acumulação internacional, mesmo quando o capitalismo ainda surgia, franzino e raquítico, numa Inglaterra que nem imaginava os planos políticos e econômicos da sua burguesia.

Os anos 1930-1950, que aqui nos interessam mais de perto, foram marcados pela plenitude do processo democrático-burguês, da ascensão do poder hegemônico da burguesia industrial no contraponto da decadência das oligarquias agroexportadoras. Evidentemente, ressalta aos olhos de qualquer historiador mais atento à categoria da totalidade $^{2}$, as contradições das lutas sociais intra e extraclasse, projetos políticos, econômicos e sociais conflitantes. Nesse sentido, na periferia sistêmica esse período é, consequentemente, o da consolidação da classe operária, da ampliação das classes médias na contramão da marginalização política e econômica do campesinato.

Não foi distinto no caso do Brasil e, por extensão da Bahia, no contexto das práticas e métodos contemporâneos promovidos pelas novas relações econômicas internacionais, na sua sanha de conservadora modernização, que impulsionava o grande capital a potencializar sua exploração através de práticas imperialistas. Internamente, tais interesses alimentavam delírios dos liberais que se questionavam acerca do enigma que não deixava o Estado da Bahia se industrializar. A desindustrialização preocupava aqueles que ocupavam posições no aparelho de estado - predominantemente liberais - no primeiro quartel do século XX, incomodados que estavam com aquilo a que denominava "enigma baiano". A resposta que encontraram dizia respeito à reprodução das relações desiguais, mas combinadas que demarcava a acumulação internacional de capitais, ou seja, nos parâmetros da modernização conservadora.

Dito isto como introdução "abrupta" e sem aprofundamento, mesmo porque este espaço não permitiria uma digressão exaustiva dos múltiplos aspectos da formação social brasileira e relacioná-los com o imperialismo presente nas relações internacionais que, desde o século XIX, marcaram o desenvolvimento do capitalismo em escala mundial, acredita-se que interrogar o passado seja uma ampliação dos horizontes de sua compreensão. Nesse ímpeto, limitar-nos-emos a traçar as grandes linhas dos fatos julgados nevrálgicos desse processo no intuito de explicar o sentido do Convênio Programa de Pesquisas Sociais Estado da Bahia - Columbia University (doravante Projeto Columbia) ${ }^{3}$ no domínio das relações que, então, envolviam o imperialcapitalismo e o Brasil, sua circunstancialidade e seus agentes, no âmbito de uma análise fundada nos umbrais da História.

\section{Integração e tutela da América Latina.}

Na primeira metade do século XX, a América Latina, por conta da crise que se manifestou contundentemente depois dos anos 1920, um projeto democrático-burguês emergiu, marcado por uma desnacionalização (particularidade da concentração do capital) dos principais meios de produção, sepultando de vez qualquer possibilidade de desenvolvimento econômico nacional autônomo. Essa preocupação foi latente em toda a 
segunda metade do século XIX, com destaque na Guerra contra o Paraguai. O corolário desse processo foi a introdução do capital inglês e depois estadunidense, que buscava tutelar as economias latinoamericanas. Nesse sentido, diversas políticas marcadas ora marcadamente diplomáticas, ora intervencionistas, muitas marcadas por apoio a golpes militares e ditaduras sanguinárias e corruptas garantiam o apoio institucional - e na maioria das vezes incondicional - aos interesses do capital monopólico internacional. Toda e qualquer nação latinoamericana, de uma forma ou e outra, sofreu o achaques do grande capital internacional. Já no século XX, conjunturas históricas: na economia, a crise dos anos 20/30; nas relações internacionais as duas guerras mundiais e seus protagonistas, assim como a Revolução Russa, delimitaram o grau e a forma das políticas imperialcapitalistas para com a América Latina. O Brasil não ficou incólume nesse processo.

Como nosso percurso busca realçar a fixação do Projeto Columbia nos planos imperialistas de inserção do Brasil no contexto da acumulação internacional de capital, este será, seguramente, o caminho que traçaremos.

No cenário dos anos 1930 - aqui tomados como ponto de partida - são referência as relações interpaíses (centro - periferia) por evidenciarem que a I Guerra Mundial não resolvera os problemas estruturais do sistema. $\mathrm{O}$ advento da profunda crise econômica daqueles anos propiciou o esfriamento das disputas interimperialistas momentaneamente, já que o contexto não oferecia possibilidades de normalidade do processo de centralização capitalista.

Mesmo tendo sofrido os reveses da crise dos anos 1920-30, os EUA continuavam uma potência em franca ascensão e com perspectivas de tornar-se hegemônica no Ocidente, num contexto de disputa multipolar com outras grandes potências imperialistas e com a União Soviética a indicar novos caminhos nas relações internacionais. Do ponto de vista das relações internacionais, portanto, o mundo dos anos 1930 estava dividido entre as grandes potências que defendiam o status quo imperialcapitalista e multipolar, mas também era o mundo da explosão do nazifascismo e do socialismo soviético. Assim, forçosamente, a tradicional ação interventora estadunidense - conhecida então como "big stick" - teve que arrefecer-se, mirando agora políticas de apoio às organizações panamericanas, ao invés das intervenções armadas diretas que, até então, sustentara no continente. Mais de um século após a Doutrina Monroe ${ }^{4}$, o país renunciava ao principal instrumento imperialista da sua relação interamericana. A nova tática de dominação que pautaria suas relações externas atendia ao epíteto de "Política da Boa Vizinhança" e buscava esfriar os efeitos negativos da crise capitalista sem empurrar as nações latinoamericanas para os braços da URSS. Nesse sentido, o "grande porrete" devia dar lugar a "acordos de reciprocidade", como o firmado em 1934, no qual os EUA deviam reduzir

as tarifas sobre manganês, castanhas e mamona e deixassem livres o café e o cacau; em troca, o Brasil reduziu os impostos sobre automóveis, rádios, baterias elétricas, cimento, tintas, frutas, peixe e outros produtos. (...) o acordo comercial era um "programa de desarmamento econômico" para as nações mais fracas. Quando importavam caminhões, carne de porco, produtos químicos etc., em vez de subsidiar essas indústrias em seu país, estavam retardando seu próprio desenvolvimento e fazendo-se vulneráveis em caso de guerra. (...) Em 1939, a administração Roosevelt estabelecera acordos recíprocos de comércio com 21 países, o que respondia por dois terços dos negócios externos americanos. (...) as exportações para os países em acordos aumentaram 63 por cento de 
1934-5 a 1938-9, enquanto, para outros países cresceram apenas a metade disso, 32 por cento. (...) Reciprocidade combinada com empréstimos era o mecanismo básico de defesa da América contra seus competidores nos anos 1930 (LENS, 2006, p. 442-3).

$\mathrm{Na}$ esfera das relações EUA/América Latina, elevava-se a vigilância contra o fascismo, o nazismo e o comunismo internacionais, ação intensificada entre os anos 193945, garantindo-se o processo de acumulação internacional sob as condições históricas que a dominação do capital inserira a região na divisão internacional do trabalho. Assim, a "Política da Boa Vizinhança" implicava a retirada de fuzileiros navais incrustados em países como Haiti, República Dominicana, Nicarágua, Filipinas, substituindo-os por milícias nacionais nas mãos de ditaduras títeres que resguardavam interesses do grande capital estadunidense sem macular a sua imagem. Em Cuba, a tentativa era mais diplomática e respondia pela nomenclatura "Emenda Platt", uma espécie de recolonização de novo modo. Mudava-se a forma da dominação, mas os objetivos eram os mesmos.

Na primeira metade da década de 1940, o governo dos EUA demonstrava especial preocupação para com o Atlântico Sul, principalmente com Argentina e Brasil, pelas manifestações de simpatia dos governos desses países ${ }^{5}$ com o Eixo ${ }^{6}$. Para aliviar a tensão, cedeu facilidades e garantias de investimentos de sua burguesia na América Latina, com o fito de afiançar as fontes de matérias-primas de que o país precisava naqueles tempos em que se especializara em exportar logística e armas para a II Guerra Mundial. Registrou Lens que,

no outono de 1940, aumentou os fundos do Eximbank, de 100 milhões de dólares, para 700 milhões, para financiar uma legião de projetos na América Latina - 45 milhões para a indústria do aço no Brasil, quarenta para as estradas no México, trinta para o programa industrial da Colômbia, 25 para Cuba e 20 para o Chile (2006, p. 457).

No entanto, aonde chegassem os dólares, chegavam também as exigências de adequação às políticas de recomposição capitalistas dos países "favorecidos". Nesse sentido, as operações econômicas previam o envio de tropas militares como suporte do processo de integração da periferia nos padrões do imperialismo multipolar. Fato é que a "Política da Boa Vizinhança" logrou o êxito de conter o Eixo na região e expandir os interesses comerciais de sua burguesia em áreas onde dominava o capital inglês. Do ponto de vista militar, a integração se fazia sob a tutela das nações imperialistas, que incentivavam a formação de um exército nacional interamericano e dependente cuja função precípua era combater o inimigo doméstico, os movimentos sociais e políticos (revolucionários e reformistas) e, ao mesmo tempo, coordenar as concessões inevitáveis aos conflitos gerados no âmbito da relação capital/trabalho.

O Brasil testemunhava os tempos do Estado Novo e um acordo diplomático entre Getúlio Vargas e Washington (denominado Acordos de Washington) criou, por decreto, em 1941, a Companhia Siderúrgica Nacional (CSN), cujo fito principal foi fornecer aço para os Aliados durante a II Guerra Mundial". Ao findar-se a "Era Vargas" em meados da década, a Confederação Nacional da Indústria (1942). Tratava-se do desenvolvimento de relações capitalistas sob as hostes de um Estado forte, auspiciado pelo capital monopólico internacional que, para se estabelecer não esquivava em disseminar golpes e instituir ditaduras em qualquer rincão que subvertesse tal ordem. Exemplo eloquente disso foi o papel exercido por multinacionais, na América Latina, como United Fruit, Standard Oil, Anaconda Copper Company, entre outras corporações. 
Apesar da marcada pauta nacional-populista do discurso em voga, o "novo" processo de industrialização estabelecido desde inícios dos anos 1930 (ISI Industrialização por Substituição de Importações) enfatizando o fim da dependência econômica da periferia ante os centros industriais desenvolvidos ${ }^{8}$, dos EUA ainda vinham, em meados de 1940: o cinema da Metro Goldwyn Mayer, acompanhado pela Coca-Cola e pelo Rock'n'roll; elevadores Otis, máquinas de datilografia Remington e Frigidaire. A Standard Oil Company of Brazil fundava, em 1946, a Companhia Nacional de Gás Esso, comandando o setor; a RCA-Victor (Radio Corporation of America) estadunidense havia se tornado companhia inseparável de qualquer cidadão comum, controlando, através de grandes corporações mundiais, a guerra de informações; uma parte do transporte público era feito por veículos automotivos fabricados pela Ford, movido por combustível importado daquele país.

Outros capitais também usufruiam da modernização conservadora que caracterizava o nacional-desenvolvimentismo brasileiro. À época, aqui se degustava pão francês feito com trigo argentino; parte do transporte público era feito por ônibus da Volvo europeia, ou por bondes alimentados pela energia da light canadense; eram tecidos obrigatórios das classes bastadas a casimira inglesa ou o linho irlandês; a calculadora mais popular era produto da sueca Facit; a alemã Wolkswagen e a francesa Simca eram os destaques da indústria automobilística; capitais holandeses e japoneses dominavam as indústrias naval e siderúrgica. E, apesar de quase $100 \%$ dos laboratórios farmacêuticos pertencerem ao capital estrangeiro (BUENO, 1980), no âmbito das relações interpaíses, preconizava-se a negação do imperialismo, assim como era quase consenso a suposta democracia racial vivenciada no Brasil, como afirmavam brasilianistas e mesmo intelectuais brasileiros.

\section{Os "Acordos de Washington".}

O sentido do Projeto Columbia University se torna mais palpável se o inserimos no contexto dos "Acordos de Washington", celebrados logo após a entrada dos EUA na II Guerra Mundial, em 1941. Como afirmado anteriormente, à época os EUA já eram uma grande potência, mas ainda dividia sua condição de nação imperialista com outros países, além de ter a URSS como grande adversária internacional, necessitando da adesão estratégica da América Latina, condição para a qual o capital monopólico não pesava esforços, desde diplomáticos até militares.

No que respeita ao Brasil, tal apoio foi fruto de barganha do Governo Vargas que, em troca do não alinhamento do país com o Eixo, acabou conseguido concessão de tecnologia e recursos financeiros, além do compromisso de construção da Companhia Siderúrgica Nacional. O torpedeamento de cinco navios brasileiros por submarinos alemães, em 1942, consagraria a adesão definitiva do Brasil ao grupo dos países Aliados. Constava, como contrapartida dos empréstimos estadunidenses ao Brasil, o fornecimento de minérios estratégicos (alumínio, bauxita, borracha, cobre, estanho, quartzo, níquel, mica, zinco, entre outros) para a indústria bélica estadunidense, escancarando as portas do país ao capital estrangeiro. Era a vez das grandes corporações supranacionais abocanharem boa parte das riquezas nacionais, também a título de direitos de patentes, transferência de lucros, tecnologia e assistência técnica, num processo de inserção periférica do país na condição de dependência do capital externo. A modernização conservadora continuava a largos passos. Eloquente exemplo disso foi o financiamento da produção de borracha com recursos gerenciados pela Rubber Development Corporation e pelo Departamento Nacional de Imigração (DNI). O capital estrangeiro e o Estado brasileiro se encarregaram de políticas de imigração para povoamento e exploração da Amazônia, com o intuito da 
extração da borracha que serviria aos propósitos da indústria estadunidense que, por sua vez, estava a serviço da guerra. $\mathrm{O}$ acordo exigia mais: a permissão de instalação de bases militares estadunidenses nas regiões Norte e Nordeste do Brasil.

Aquilo que se entendia por desenvolvimento industrial, não só do Brasil, mas da América Latina como um todo, se faria, basicamente, sob a influência do grande capital estadunidense - dado a perda de hegemonia inglesa - que passaria a controlar a indústria nacional. Os setores políticos hegemônicos latinoamericanos intensificaram seu apoio aos interesses do grande capital estadunidense, alternando-se em golpes, ditaduras militares e regimes de democracia representativa burguesa, garantindo a "ordem" contra as pressões operárias e populares que, diziam, corroíam a taxa de lucro (Hayek, 1946) ${ }^{9}$.

Na perspectiva da Doutrina Truman (1947), entendia-se que o modo estadunidense de administrar o capitalismo só sobreviveria caso se tornasse mundial. Nesse aspecto, o dólar deveria impor-se como moeda de pressão política, instrumento de interferência nos negócios internos de outros países: as "ajudas" estadunidenses deveriam servir "para deslocar o centro de gravidade político para a direita" (LENS, 2006, p. 524). Assim, a "diplomacia do dólar" devia envolver compromisso de fidelidade para com o anticomunismo (como princípio das relações internacionais) e a Lei de Segurança Nacional (que, internamente, apontava os inimigos do sistema capitalista). Fato é que tal diplomacia financiou a derrubada de governos (Guatemala, Irã, Bolívia, Guiana Inglesa, Indonésia, Camboja), tentou invadir de Cuba (1961), apoiou governos conservadores no Congo, Vietnã, Laos, Tailândia e Etiópia.

Assim, do ponto de vista militar, a América Latina seria consolidada como um só bloco, através do Tratado Interamericano de Assistência Recíproca (TIAR), composto de 21 países (20 da América Latina, mais os EUA). Não é demais registrar que armamentos advindos de recursos da assinatura do TIAR foram utilizados para reprimir movimentos antissistêmicos e de oposição no Brasil, Argentina, Paraguai, Bolívia, Peru, Colômbia, República Dominicana..., entre outros.

No período da II Guerra Mundial, tais políticas ganharam eficácia e sistematicidade tamanhas que a dominação se pautava mais nas influências culturais, tecnológicas e ideológicas (derivadas do american way of life) que na intervenção armada, o que não negava a recorrência a esta quando a dominação não podria se dar de outra forma. Uma vez amenizada a crise, capitais estrangeiros penetraram massivamente a periferia, representados pelas corporações multinacionais que visavam integrar as economias nacionais periféricas aos centros capitalistas, de modo a ampliar as bases sociais das classes dominantes. Com isso, a burguesia interna da América Latina abriu mão da constituição de um mercado autônomo, atuando como títere dos interesses das corporações multinacionais.

No final de 1956, os investimentos estadunidenses no Brasil só perdiam para o Canadá e para a Inglaterra. Em apenas três anos (1957-60), 400 empresas estadunidenses instalaram-se no país. Os "Acordos de Washington" atingia seus objetivos. Mas, voltemonos para o "Programa de Pesquisas Sociais Estado da Bahia - Columbia University"10.

\section{O Convênio Colúmbia University e a modernização conservadora na Bahia.}

Cremos que, mesmo que sucintamente, esta rápida - e julgada necessária - revisita às principais acomodações das economias periféricas - fundamentalmente para este ensaio a da América Latina - no campo da acumulação internacional de capitais pode evidenciar as linhas gerais dos agentes protagonistas desse processo e fornecer informações acerca do 
cenário internacional em que se inseriu o Projeto Columbia. Nesse sentido, cumpre destacar:

1) As transformações ocorridas em escala mundial, como o relativo urbanismo e o acelerado crescimento populacional - principalmente nos centros capitalistas e, em menor escala, nas denominadas regiões 'agrárias' da periferia -, estimulados pelo processo de industrialização, atraiu a população rural para centros geoeconômicos, proporcionando à burguesia disponibilidade de mão de obra. No que concerne ao Projeto Columbia, esse contexto foi tomado como um dos elementos-chave na definição dos elementos de estudo das comunidades-foco. A escolha das cinco comunidades a serem pesquisadas levava em conta, mesmo que não explicitamente, uma estratégia pródiga para a expansão capitalista no Estado. Quem estruturou tal estratégia foi a UNESCO (Organização das Nações Unidas para a Educação, Ciência e Cultura), em colaboração com a Columbia University e a então nascente Universidade Federal da Bahia, a partir dos primeiros anos 50, como afirma Sansone (2005-2006). Devia tratar de contextos sociais distintos aos quais se aplicariam os estudos de relações raciais, enfocando as mudanças sociais. Além de estudar as "elites de cor" da cidade de Salvador, devia ater-se ao estudo de comunidades tidas como rurais, "atrasadas". Atente-se para o teor ideológico do termo num contexto em que faz dicotomia com "desenvolvido" que era tido como sinônimo de modernizado, industrial. Tais parâmetros induzem a um sentido de integração das diversidades, representadas nas diferentes regiões geográficas e sociais da Bahia (Uruçuca - região cacaueira baiana; Chapada Diamantina, região cuja história econômica se fundou na mineração, tendo como centro a cidade de Rio de Contas; Monte Santo - comunidade do sertão árido, mas com experiência na agricultura de subsistência; e o Recôncavo, destacada e histórica zona de produção canavieiro-açucareira).

Sansone (2005-2006) chama a atenção para um fato relevante: a cidade de São Francisco do Conde ${ }^{11}$ foi, entre 1550 e 1950, foco de desenvolvimento açucareiro e, de 1950 até os dias de hoje, de destacada produção petrolífera. Por que relevante? É sabido que, desde início do século XIX, capitais estrangeiros (primeiramente inglês e depois estadunidense) almejam explorar petróleo no Brasil. Victor (1991) traça a trajetória histórica da descoberta do petróleo na antiguidade, de sua exploração por distintos povos até chegar à sanha gananciosa do capital monopólico, chegando à exploração e domínio da produção do petróleo brasileiro. Tem-se registro de descoberta de petróleo no Brasil no sul da Bahia (Maraú, Ilhéus, Valença...) na década de 1860. Á época sob os auspícios do Governo do Império Português, passando pela formação dos grandes trustes estrangeiros do petróleo (destacadamente Standard Oil e Royal Dutch-Shell) a busca pela apropriação dessa commodity tratou-se de uma verdadeira guerra na qual a América Latina era enquadrada nos mesmo padrões neocoloniais. A estratégia imperialista era aliciar governos ditatoriais e corruptos pró-estadunidenses (VICTOR, 1991, pp. 117-119). Dos anos 1930 aos 50, o Brasil não era uma exceção nesse processo, apesar das peculiaridades que lhe eram inerentes, sendo travada uma luta política-diplomática entre grupos econômicos internos e estrangeiros, que minavam as hostes governistas, inclusive os setores declarados 'nacionalistas'. O processo culminou com a fundação da Petrobrás, em 03 de outubro de 1953.

Diante de tais informações, ressaltamos a importante coincidência econômica de São Francisco do Conde - e adjacências - nesse contexto de lutas intestinas entre os mais diversos interesses da burguesia interna e internacional, através de seus trustes e dos governos de plantão. A produção de petróleo no Recôncavo baiano, no entanto, começou a ganhar corpo com a construção da Refinaria de Mataripe, já em 1949, mas já havia estudos 
de viabilidade anteriormente desenvolvidos. A pergunta que não se cala é: até que ponto os estudos de comunidade gerados pelo Projeto Colúmbia contribuíram, também, para isto, já que os anos 1950 foram cruciais para a industrialização petrolífera no país. A vocação econômica da cidade em desenvolver produções de forte interesse do mercado internacional (duas commodity's como açúcar e petróleo) chama nossa atenção, mas também o fato de a Companhia Nacional do Petróleo ter passado a explorar ali o petróleo em 1950, período que remete aos resultados dos estudos de comunidade do Projeto.

2) Os estudos de comunidade que chegaram ao Brasil na década de 1930, elaborados nos padrões da Antropologia Cultural estadunidense por meio de acordos de cooperação técnica oportunizaram a muitos antropólogos daquele país atuarem em projetos de "desenvolvimento" de comunidades de extensão rural, saúde pública, nutrição e educação sanitária em países da América Latina. Ao final da década de 1940, antropólogos estadunidenses inovaram ao produzir um saber voltado para o campo das políticas de saúde pública e dos programas de introdução e difusão da medicina em lugares onde prevaleciam formas tradicionais (não existiam serviços médicos) de lidar com as doenças. Portanto, os "antropólogos do governo" (como eram chamados) tinham convicção de que os estudos etnográficos contribuiriam para o sucesso de políticas que visavam obter a adesão das comunidades locais aos preceitos da medicina preventiva, bem como induzir sua participação nos programas de saúde comunitária (SVERSUTI \& ALMEIDA, 2011). O intuito dessas políticas de saúde e desses programas de introdução e difusão da medicina em lugares onde prevaleciam formas tradicionais de lidar com as doenças talvez seja parte da explicação do domínio dos laboratórios estrangeiros no país nos anos subsequentes. Assim sendo, foi por meio, também, dessa nova visão do conhecimento antropológico que os Estados Unidos obtiveram informações que contribuiriam na administração de sua política intervencionista no subcontinente. É possível venha daí o ponto forte dos interesses do Projeto Columbia em pautar-se nas questões da saúde e da educação na Bahia.

A pesquisa, como mostram os questionários e fontes levantadas pelo Museu Pedagógico da UESB no âmbito do Projeto "Revisitando o Programa de Ciências Sociais no Estado da Bahia - Colúmbia University", desenvolvido em parceria com pesquisadores da PUC-SP, UFSCAR e UNICAMP, teve caráter etnológico. No entanto, levando em conta o estágio de desenvolvimento da acumulação internacional e o contexto histórico daquela conjuntura, pela concatenação de interesses e pelas políticas imperialistas às quais a América Latina como um todo estava circunscrita, vê-se que coincidia com interesses econômicos nativos e estrangeiros, como mostrou a própria história que se seguiu. Tem razão Medeiros (2009, p. 98) quando afirma que

\begin{abstract}
ausente do direcionamento teórico não estava a concepção, que gradativamente foi ocupando o pensamento dos economistas de que as sociedades tradicionais passariam pelo mesmo processo de desenvolvimento das sociedades capitalistas ocidentais mais influentes.
\end{abstract}

3) Rio de Contas, uma das comunidades-foco escolhidas pelo Projeto Columbia, não passou despercebida por seus agentes executores. Num contexto de estruturação produtiva em que a introdução da força de trabalho feminina no processo de produção era um fator possibilitador da exploração à qual o capital impunha salários inferiores ao masculino, Harris (1956) destacou o papel desse elemento - assim como o trabalho infantil na comunidade de Rio de Contas - àquela época. Observou ele que a imigração dos trabalhadores que se destinavam aos centros urbanos paulistas e paranaenses, quando da 
abertura de fronteira agrícola nessas regiões, causava impacto social e sexual na divisão do trabalho daqueles que ficavam na comunidade. Escreveu:

Na faixa de idade entre vinte e cinquenta anos, o grupo em que a maior parte da atividade econômica depende, há apenas 162 homens, mas há 319 mulheres - duas mulheres para cada homem. Esse fato explica, porque há tantas mulheres na terceira classe, ou classe baixa que são chefes de família (HARRIS, 1956, p. 94).

A percepção e atenção envidada a fatores determinantes e prementes à produção capitalista não podiam passar despercebidos, e a existência desse fator diz respeito à oferta de condições e possibilidades reprodutivas da acumulação de capital nos padrões internacionais de então. Tais preocupações indicavam haver, no Brasil - e mais especificamente na Bahia -, elementos constitutivos de uma integração interna, por mais dissonantes que fossem as etnias e as diferenças sociais. Paradoxalmente, tais dissonâncias facilitavam a sua integração às condições de exploração do capital oriundo dos centros capitalistas.

4) Outro elemento que chamou a atenção dos estudiosos das comunidades estrategicamente eleitas foi o da possibilidade de geração de um desenvolvimento técnicocientífico de organização produtiva capaz de proporcionar uma maior e mais rentável produção. Harris (1956, p. 48), estudando a indústria do couro da região da Chapada Diamantina, via nela a possibilidade de introdução de tecnologia movida a motor, em substituição à oficina domiciliar, incorporando uma administração empresarial nos padrões fordistas.

Em linhas gerais, estas são algumas questões candentes que as evidências históricas apontam para o caráter imperialcapitalista do Projeto Colúmbia. A Educação trata-se também de outro aspecto no mesmo sentido.

\section{O Projeto Columbia e o papel da educação na periferia sistêmica.}

Entendendo que a educação formal, em qualquer época histórica, atende aos interesses dos grupos hegemônicos de toda e qualquer formação social, a simbiose educação/economia/cultura/sociedade, cristalizada nos princípios do liberalismo, não foi diferente no Brasil. Assim entendendo, não é despropositada a ênfase aqui dada aos interesses burgueses, nativos e estrangeiros, no processo de integração da América Latina, nos padrões da modernização conservadora, ao processo de acumulação internacional de capital.

É fato histórico que a constituição da burguesia na periferia (destacadamente a América Latina), em nenhum momento se fez por ruptura com o latifúndio. Pelo contrário, foi fruto de acomodações que viabilizaram a incorporação das oligarquias à ordem burguesa industrial e financeira. Prova disso foi a capitalização da grande propriedade fundiária, fato que levou a um herança econômica agro mercantil até hoje representativa nacionalmente, haja vista o predomínio da agro exportação no conjunto da economia brasileira. 
Para viabilizar tal conservadora modernização, interessava ao setor industrial qualificar uma quantidade de mão de obra que atendesse as demandas econômicas da nova configuração de inserção da periferia no processo de acumulação internacional de capital. À educação formal caberia desenvolver, estruturalmente, um ensino técnico que respondesse ao problema da industrialização tardia, propósito que se encontrava para além do ensino das antigas escolas de aprendizes e artífices, voltadas para a instrução de ofícios artesanais (alfaiates, sapateiros, marceneiros...).

O novo ensino técnico deveria atender às aspirações profissionais de novo tipo (aprendizagem pautada na racionalização da organização industrial) e formar trabalhadores com qualificação para a diversificada estrutura industrial do país. Nessa condição, o Estado teria que ceder espaço para o controle patronal do ensino técnico, que daria início a uma nova estrutura de instrução industrial (RIBEIRO, 2009). O intuito, com isto, foi promover a qualificação da mão de obra nos padrões exigidos pela expansão industrial do pós-II Guerra Mundial (destaque para a indústria petroquímica e metalmecânica).

No Brasil, tais mudanças foram explicitamente expressadas no Manifesto dos Pioneiros da Educação Nova, de 1932. Aliás, a década de 1930 foi particularmente fértil para os discursos reformadores dos partidários da educação nova. A fidelidade aos princípios liberais republicanos convertia toda a heterogeneidade dos atores envolvidos com o Manifesto num único pensamento social devotado à defesa da escola pública (FREITAS, 2009, p. 177). Os processos históricos da crise capitalista e seus efeitos e consequências, arrolada aí a "Revolução de 30" (acerca ver Hilton, 1982), implicaram, para além dos discursos liberais, a intervenção estatal. O Estado passava a principal interlocutor entre os capitais externo e interno quando o assunto dizia respeito a questões interrelacionadas ao ensino-aprendizagem e desenvolvimento econômico (com incidência para a esfera industrial). Freitas (2009, p. 178) é enfático ao afirmar que o

Manifesto [dos Pioneiros], portanto, não é um ícone de vitória da escola
pública, mas um marco do quanto sua imagem reverberou nos alinhavos
que teciam uma esfera pública frágil ao lado de uma burocracia estatal
cada vez mais vigorosa. (...). [O Manifesto] sinalizava para uma ruidosa
movimentação política ao redor do tema "República incompleta". (...)
Fazia coro com uma argumentação convencida do caráter inconcluso da
República e, ainda que com contradições, sinalizava que a disseminação
da escola pública deveria ser considerada o dado ausente, a lacuna a ser
preenchida. (...) [Abrigava] uma retórica constitutiva de um grupo que
não era grupo e de "técnicos" que se apropriavam da técnica para fazer
política, revelava, nas suas entrelinhas, a vulnerabilidade com a qual o
tema escola pública estava posicionado nas rubricas orçamentárias, nos
parágrafos jurídicos normativos, nos púlpitos e palanques e nos
"chamamentos à nação".

Apesar dos discursos autonomistas do Manifesto e das políticas públicas federais no sentido de converter o ensino-aprendizagem em qualificador da mão de obra demandada pela indústria, tal modelo não rechaçava a herança colonial da "troca desigual" aludida por Emmanuel (1981) entre os centros desenvolvidos e a periferia do sistema, reproduzindo, no novo cenário, a extração de excedentes econômicos segundo os interesses do capital monopólico. Pelo contrário, o ratificava e dava fôlego quando as políticas públicas indicavam que o rumo de nossa economia devia ser agroexportador. Isto implica dizer que as economias nacionais teriam que buscar a intermediação entre a sua herança colonial agrárioexportadora e produzir artigos duráveis a partir de um processo de 
industrialização dependente da tecnologia estrangeira. Nesse sentido, a novidade que atendia pela sigla ISI não poderia romper com o ciclo vicioso da acumulação internacional de capitais. Assim, o capital nativo, pertencente à burguesia agroexportadora - e que não fora destruído pela crise dos anos 1930 -, passou a ser canalizado para o setor industrial. Das implicações diretas desse processo estava pôr em curso uma mudança na estrutura de classe das economias periféricas no âmbito nacional: entrava em cena uma burguesia liberal, cujo intuito era assediar a já combalida hegemonia das oligarquias, sem, no entanto, rechaçá-la do processo global de acumulação. Assim devia ser concretizada a modernização conservadora na periferia sistêmica.

Desse modo, ganhou força a imposição de políticas econômicas e culturais que tinham como escopo a adesão ao American way of life, o que sugeria aderência à escala de valores e comportamentos típicos da sociedade estadunidense. Importava-se, assim, a produção em massa e seu parceiro inseparável, o consumismo; também os padrões estéticos, ditados principalmente por Hollywood; o uso da tecnologia em moda (rádio, fonógrafo, grande imprensa...) etc. Nesse contexto, junto aos produtos culturais e tecnológicos que entravam via portos e centros acadêmico-científicos, por contrapeso entrava também a aquiescência à ideologia da inferioridade de raças, o que acabava formatando e convencionando conhecimentos ditos 'científicos', que atingia e influenciava educadores, cientistas sociais (antropólogos, principalmente), publicitários e intelectuais diversos. Assim emergiam estudos acerca da formação do povo brasileiro, o que implica dizer, da mistura do índio, do branco e do negro. Aliás, já havia conquistado espaço a primeira grande referência no gênero: "Casa-Grande \& Senzala", do sociólogo e antropólogo Gilberto Freyre, cuja primeira edição fora publicada em dezembro de 1933, período entre - guerras em que o conceito de identidade tinha um grande peso para o domínio cultural e político.

Internamente, tais valores transitavam por via das mudanças socioeconômicas trazidas pela crise das oligarquias agroexportadoras e pela emergência de um Brasil urbano-industrial, ainda que raquítico; e, externamente, pelo predomínio da ideia de superioridade do branco sobre as demais etnias, doutrina-base da ideologia do nazismo. Gilberto Freire, com Casa Grande \& Senzala; Sérgio Buarque de Holanda, com Raízes do Brasil; e Caio Prado Júnior, com Formação do Brasil Contemporâneo, entre outros, 'reinventavam' a História do Brasil. Principalmente estas três obras exprimiam a radicalidade com que intelectuais, através da literatura, não mediam esforços para forjar a identidade nacional. Foram produções fruto de uma análise social que privilegiava os estudos da cultura afro-brasileira, eclodida depois da denominada "Revolução de 30", mas contida pela ditadura varguista do Estado Novo. Para Antônio Candido,

Casa-grande e senzala é uma ponte entre o naturalismo dos velhos intérpretes da nossa sociedade, como Sílvio Romero, Euclides da Cunha e mesmo Oliveira Viana, e os pontos de vista mais especificamente sociológicos que se imporiam a partir de 1940. (...) em virtude da preocupação do autor com os problemas de fundo biológico (raça, aspectos sexuais da vida familiar, equilíbrio ecológico, alimentação), que serviam de esteio a um tratamento inspirado pela antropologia cultural dos norte-americanos, por ele divulgada em nosso país (CANDIDO, 1995, p. 10).

Para Maranhão (2004, p. 1), dentre as obras aqui citadas, 


\begin{abstract}
é Casa-Grande \& Senzala que causa maior impacto à época. Ao retomar a temática racial sob a perspectiva teórica da antropologia cultural norteamericana (leia-se Franz Boas), Gilberto Freyre afirmava o papel positivo da mestiçagem na formação da nacionalidade brasileira, invertendo o valor que até então lhe era atribuído pelas teorias e análises sociais formuladas entre meados do século XIX e o início do XX por autores como Silvio Romero, Nina Rodrigues e Oliveira Vianna.
\end{abstract}

Outros nomes recém-despontados são lembrados por Maio (1999) nessas análises, como Florestan Fernandes, Thales de Azevedo, Luiz Aguiar da Costa Pinto (da Universidade do Brasil), Oracy Nogueira, René Ribeiro. Vultos já consagrados, como Roger Bastide ${ }^{12}$ e Charles Wagley também figuravam nesse cenário, tendo como importantes referências Gilberto Freyre e Donald Pierson. Outros, então jovens estudantes estadunidenses chegados em 1952 podem ser agregados, como Marvin Harris, Harry William Hutchinson e Ben Zimermann. Como se percebe, a maioria desses nomes tem relação direta ou indireta com o Projeto Columbia.

Preocupado com a modernização e industrialização da Bahia, o educador liberal Anísio Teixeira não entendia porque este Estado não conseguia adentrar o eixo da modernização que se espraiava pela periferia capitalista. No entanto, tinha clareza de que era imprescindível expandir a educação a toda a população de forma a atender à demanda capitalista, o que implicaria adequá-la à estrutura urbano-industrial. É possível não estivesse ao seu alcance o entendimento de que a educação em massa e a disseminação dos meios de comunicação, idem, seriam os elementos viabilizadores desse processo de industrialização. No entanto, o que se viu foi a manipulação do conhecimento segundo os interesses da acumulação, possibilitando, a um só tempo: 1) a concepção de uma educação formal capaz de desenvolver um amplo contingente de mão de obra com relativa qualificação técnica para a indústria, priorizando a preparação dos indivíduos para o mercado, adequando a periferia às transformações econômicas; 2) a manipulação da 'opinião pública' (publicizada), propiciando um fluxo maior de informações, funcionando como aparelho ideológico na garantia de manutenção do status quo. O necessário conhecimento dos hábitos, costumes, etc., locais e regionais para adequá-los à lógica do grande capital, seria a precípua tarefa que os Estudos de Comunidade cumpririam na Bahia, marcada pelo "enigma" da desindustrialização.

\title{
A crise estrutural e a ISI na América Latina.
}

A crise estrutural capitalista que marcou os anos 1930-1940, na América Latina evidenciada na redução temporária de sua capacidade de exportação de produtos agrários e importação de bens de consumo, acabaria por forçar a formação de um mercado interno para as manufaturas nacionais. Na periferia, alguns países (Brasil incluso) já tinham desenvolvido um incipiente mercado interno e organizado um - também incipiente sistema produtivo industrial nos padrões capitalistas ${ }^{13}$ de então.

Aproveitando-se da crise econômica e do vácuo da guerra, setores da burguesia periférica passaram a impulsionar a ISI como modelo de inserção no mercado internacional, investindo na produção industrial dependente do capital estrangeiro. Antes mesmo da crise de 1929, quase a totalidade das empresas instaladas na América Latina, assim como o setor de serviços básicos, era detida pelo capital estrangeiro ${ }^{14}$, situação que imprimia condições desfavoráveis à formação de um mercado interno autônomo. Em consequência dessa configuração, o crack na Bolsa de Nova York levou as filiais dessas 
corporações a uma perda de liquidez que repercutiu na estrutura das relações econômicas engendradas até então com a periferia, fazendo com que esta buscasse se reconstituir economicamente.

O processo de ISI, subsequente à crise, indicava que a América Latina atingiria uma considerável autonomia econômica com os incentivos à criação de uma indústria de bens de consumo genuinamente "nacionais". No entanto, a racionalização da organização industrial em que se pautava a qualificação/desqualificação dos aprendizes e mestres deveria seguir o padrão taylorista então em vigência na produção industrial internacional. Esse padrão, por sua vez, implicava a implantação de um modelo organizacional montado nas relações imperialistas (no que dizia respeito à distribuição geográfica de unidades produtivas, sugerindo uma disposição multinacional de ancoragem da produção capitalista). Em outras palavras, o modelo de organização industrial que se adotava na periferia buscava reproduzir um padrão de organização propícia à reprodução tipicamente imperialcapitalista da modernidade conservadora.

\section{A readequação capitalista pós-guerra e a relação UNESCO/Columbia}

No imediato pós II Guerra, forjou-se no seio do imperialismo estadunidense um complexo cujas operações se interpenetravam. A recomposição capitalista foi sistematicamente configurada na Conferência Monetária e Financeira, ocorrida em Bretton Woods (EUA), em julho de 1944. Lá foi constituído o FMI (Fundo Monetário Internacional) e o Banco Mundial. Um ano depois, surgiria a ONU (Organização das Nações Unidas), com vistas a atuar no campo diplomático internacional. Posteriormente, em 1947, para controle comercial, foi criado o GATT (General Agreement on Tariffs and Trade) futura OMC. Nas questões sindicais, foi formada, em 1955, a AFL-CIO (American Federation of Labour-Congress of Industrial Organizations), federação de sindicatos autônomos dos EUA, Canadá, México, Panamá e dependências estadunidenses. Internamente, dezesseis organizações subsidiadas pelo Departamento de Defesa, popularmente conhecidas por "think tanks", como a Rand Corporation, surgida em 1945, com o fito de pesquisar em inúmeras áreas, inclusive as das Ciências Sociais, e formular estratégias para o Pentágono. Lens (2006, p. 561) chega a afirmar que os militares financiaram enorme quantidade de projetos de pesquisa social com o propósito de ganhar para si mesmos e seus programas uma imagem favorável perante seus cidadãos.

Nessa conjuntura, a educação não deixou de ser pensada como mola propulsora para a adequação social dos povos nativos da periferia sistêmica aos padrões econômicos e políticos que a recomposição imperialcapitalista impunha. A industrialização dependente que se desenvolvia na periferia necessitava de inovações educacionais num cenário em que a força de trabalho também se adequasse qualitativamente à reestruturação produtiva, num terreno "atrasado" (semicolonial), para os padrões internacionais, e desconhecido até então (os relatórios do Projeto Columbia o demonstraram). Quando se referiam às dificuldades de industrialização da Bahia, o discurso em voga à época traduzia isso como o "Enigma Bahiano". Discurso somente superado na década de 1960, no contexto do projeto nacionaldesenvolvimentista. No entanto, há quem tenha dito, posteriormente, que a sociedade brasileira mostrava-se em "acelerado processo de modernização capitalista" (MAIO, 1999).

A nosso ver, e a História o mostrou, a UNESCO, criada em 1945, tinha como primeira função fomentar um projeto de recomposição sistêmica na periferia. Pretensamente concebida como promotora "da paz e dos direitos humanos com base na solidariedade intelectual e moral da humanidade"15, a UNESCO não nasceu da 
benevolência ou filantropia do grande capital internacional, como o romantismo dos direitos humanos ressalta. Pelo contrário, foi configurada enquanto agência internacional para a regência de políticas educacionais na periferia capitalista, cujo procedimento vinha travestido de "cooperação técnica" entre os países membros. A partir de 1950, ela assumiria, abertamente, seu interesse pelo processo de industrialização dependente da periferia, numa conjuntura em que os termos repetidos ad nauseam eram desenvolvimento/subdesenvolvimento, envidando esforços (recursos e logística) em pesquisas que focassem o industrialismo no Brasil e seus aspectos mais gerais. Seu intuito, dentre outros, era desenvolver políticas articuladoras entre ciência e tecnologia através da educação. Vão nesse sentido as "recomendações/orientações da UNESCO" com vistas à sua inserção no reordenamento capitalista pós-II Guerra ${ }^{16}$. A ela interessava os estudos das relações raciais no Brasil, focados nas unidades federativas da Bahia, Rio de Janeiro, Recife e São Paulo. O Projeto Columbia, nesse contexto, "especialmente quanto às preocupações de parte da elite com o "Enigma Bahiano", [...] cumpria conhecer a realidade da Bahia como passo importante para entender-se possibilidade de mudança" (MEDEIROS, 2009, p. 97).

Nesse "destino manifesto" da recomposição capitalista, a academia também necessitava estar ao lado do Pentágono. Assim, a Universidade de Columbia seria peça importante a ser inserida nesse processo. De histórica tradição nas Ciências Sociais, com destaque para a etnografia, a historiografia e a antropologia (no que coincide com os eixos temáticos da UNESCO), a Columbia University sempre gozou de inegável influência na esfera política dos EUA, fato comprovado pela presença de um de seus reitores (19481953) na Presidência da República (1953-1961): Dwight D. Einsenhower ${ }^{17}$, apesar da falta de qualificação acadêmica por este apresentada.

Ora, o histórico da Columbia University conspira contra ela no que respeita à sua relação com o Estado imperialista de seu país. Aliás, o envolvimento de centros universitários estadunidenses com as ações imperialistas de seu Estado não são novidades. Lens (2006, p. 579) registra, a posteriori, o Projeto Camelot, estreado pela American University em inícios de 1962, que focalizava "áreas conturbadas" como o Chile, Quebec, Brasil e mais uma dezena de outras. Lens (2006, p. 558) fala, ainda, de escolas

como o Instituto de Tecnologia de Massachusetts (MIT), a Johns Hopkins e os "centros de contratação" dirigidos pelas universidades de elite. Quase 1,25 bilhão de dólares por ano era canalizado do Pentágono, da Comissão de Energia Atômica e da NASA - Administração Nacional de Aeronáutica e do Espaço para a educação superior. Em 1967-8, o orçamento de pesquisa e desenvolvimento do MIT foi de 174 milhões de dólares, 90 por cento dos quais vindos dos cofres do governo federal, sendo que 125 milhões provinham de recursos para a defesa. O MIT, naturalmente, era o nec plus ultra da colaboração acadêmica com os militares, mas, em 1967, outras universidades também receberam parte desses recursos: 20 milhões para Michigan, nove milhões para Harvard, mais de 70 milhões para a rede da Califórnia, 18 milhões para Illinois, sete para Yale, 18 para Columbia [grifo nosso] e 11 para Princeton.

Tal envolvimento, como não poderia ser diferente em se tratando de uma instituição estatal, tinha o propósito de influenciar os rumos de suas políticas internas. Nesse conjunto de fatos que se interpenetram, o Brasil representava uma escolha estratégica para o processo de acumulação planetária de capital. Isso para citar a relação entre capital e 
Estado no que respeita à Educação e à Ciência, arrolamento que inclui aí o Projeto Columbia.

Tanto a UNESCO quanto a Colúmbia University tinham, então, tradição em Antropologia, o que as conduziram (já entre 1951-53) à apropriação de estudos, análises sociológicas e antropológicas, assim como de acervos e dados então produzidos sobre o negro no Brasil. No entanto, é necessário registrar, as pesquisas aí elaboradas, de predominância da etnologia até finais dos anos 1940, davam ênfase a uma suposta ausência de conflitos raciais e minimizavam o preconceito de cor. Suas contribuições dizem respeito à nova fase dos estudos fundados na perspectiva teórico-antropológica de Franz Boas (1858-1942).

Explicitada em escala global, a recomposição capitalista do pós-II Guerra, por tudo o que se disse anteriormente, mas também pelo Plano Marshall de reconstrução da Europa; pela Doutrina Truman; pela Constituição Brasileira de 1946, que avançou nas liberdades individuais e pela presença marcante do antropólogo Gilberto Freire; pela presença de Anísio Teixeira na UNESCO (1947); pela criação do Programa de Pesquisas Sociais Estado da Bahia, em 1950, que se incumbiria de encetar os estudos de comunidades com base nos eixos de raça e classes (CONSORTE, 1997); pelo intercâmbio e preparação de educadores $(1950)^{18}$; pelas recomendações da UNESCO de financiamento da educação (1955); pelas políticas educacionais do presidente Juscelino Kubitscheck (1956-1961); pela compreensão da educação centrada na dualidade urbano/rural (1958); e pelo recrutamento de quadros técnicos (1959), um conjunto de fatos aponta grande parte dos elementos de nexo entre a recomposição capitalista em escala mundial e a inserção do Brasil nesse contexto. O Projeto Columbia University - Estado da Bahia foi mais um elo dessa corrente.

A relação entre o Estado brasileiro e o capital estrangeiro que entrava alvissareiro no país se explicita no Relatório Financeiro e de Despesas do Programa de Pesquisas Sociais do Estado da Bahia - Columbia University ${ }^{19}$, datado de 22 de abril de 1953, referente aos anos 1949 a 1953. Nele, o professor Thales de Azevedo faz distinção da origem das verbas empregadas, situando a fonte dos recursos como proveniente de organizações estadunidenses, tais como: "Social Science Rearch Council, Viking Fund (Werner Green Foundation), Dougherty Fund"; e a recursos liberados pelo governo do Estado da Bahia, por meio da Secretaria Estadual de Educação e Saúde. Também exibe as organizações patrocinadoras do Projeto: a Universidade de Columbia, a Secretaria de Educação do Estado da Bahia e a Fundação para o Desenvolvimento da Ciência, na Bahia (através da Lei $\mathrm{N}^{\mathrm{o}}$ 347, de 13 de dezembro de 1950) - esta criada justamente para administrar o Convênio.

Ao mesmo tempo, a vanguarda desse ousado Projeto, composta por figuras eminentes da política e da educação baianas, como o professor e Secretário de Educação do Estado da Bahia, Anísio Teixeira, e o Dr. Thales Olympio Góes de Azevedo (representante do Governo do Estado no Convênio), da Universidade da Bahia; Charles Wagley (representante da Columbia University) ${ }^{20}$ e Marvin Harris apontam a perspectiva liberal de sua execução e sua pertinência imperialcapitalista.

Esta pequena turnê nos permite afirmar que as citadas transformações, impulsionadas a partir da inter-relação capital/trabalho, acabariam por incorporar-se às formas de produção que dariam os rumos da sociedade capitalista na periferia. Nesse processo, o Projeto Columbia foi um elemento importante para a superação daquilo que o então Governador da Bahia, Otávio Mangabeira (1947-51), identificava como "Enigma Bahiano". Sua superação, identificada pelo nacional-desenvolvimentismo tinha a marca da modernidade conservadora que marcou a inserção da América Latina no processo de acumulação internacional de capitais. 


\section{Considerações Finais.}

O ponto de partida da premissa central desse artigo foi buscar entender a inserção da América Latina no processo de acumulação capitalista e, nesse contexto, o Estado da Bahia, cuja precípua preocupação dos governantes tinha referência ao "enigma bahiano". Desde os anos 1930, o capital monopólico estadunidense, em parceria com o aparelho de Estado da Bahia passou a investir em pesquisas que desvendasse a charada da desindustrialização reinante na Bahia, o que implicou especial atenção (traduzida em pesquisas) acerca do industrialismo no Brasil e seus aspectos mais gerais.

No âmbito acadêmico, esse caráter mais geral foi responsável por investigações e relatórios atinentes à comunidade baiana de economia tradicional (pesquisas concentradas em zonas consideradas representativas: Alto Sertão, Recôncavo, zona de transição Recôncavo - Sertão e Região Cacaueira), mas também sobre economias modernizadas do Sudeste do Brasil (Rio de Janeiro e São Paulo) e de potencial natural (Amazônia).

É necessário registrar que, até a I Guerra Mundial, as Ciências Sociais, na Bahia, eram produzidas por médicos e bacharéis influenciados pelos determinismos geográfico e racial (MAIO, 1997, p. 76), realidade parcialmente subvertida entre os anos 1930-40 pelas investigações de pesquisadores estrangeiros (idem, pg. 77), não por acaso de predominância estadunidense. Parcialmente, porque as pesquisas aí elaboradas, de predominância da etnologia até finais dos anos 1940, ainda davam ênfase a uma suposta ausência de conflitos raciais e minimizavam o preconceito de cor. À época, Salvador era considerada a terra da harmonia das raças (MAIO, 1997, p.74). Nesse ímpeto, cientistas sociais estadunidenses e brasileiros, envoltos sob o patrocínio da UNESCO, desenvolveram pesquisas que se tornaram referências para outros estudiosos (acerca ver MEDEIROS, 2009). Mais, envolveu diversas autoridades das Ciências Sociais de reconhecimento internacional, como Alfred Metraux (1902-1963), então chefe da Division for the Study of Race Problems, da Unesco, que também, idilicamente, concebia como harmoniosas as relações inter-raciais estabelecidas no Brasil (CANCELLI, 2010).

Os propósitos se casavam. No governo interventor de Landulfo Alves (1938-1942) foi criada a Faculdade de Filosofia da Bahia, cuja iniciativa para a inauguração foi o convite ao antropólogo estadunidense Melville Jean Herskovits (1895-1963), para quem a Bahia representava, no Novo Mundo, referência de tolerância racial (apud MAIO, 1997, p. 77). Apesar dessa gênese, a criação da Faculdade inauguraria o que viria a ser uma nova fase para as Ciências Sociais da região. Claro que ainda se passaria bastante tempo para que a tradicional prática médica antropológica iniciada no século XIX, que legara tantos nomes expressivos da antropologia brasileira como Nina Rodrigues, Artur Ramos, Roquete Pinto, e tantos outros, fosse superada. Prevalecia, ainda, uma antropologia caracterizada pela análise e observação, com fundamentos na evidência empírica e objetiva, não raro em perspectiva histórica e fundada não apenas na intuição.

Nesse sentido, em 1943, o médico Thales de Azevedo, amigo e contemporâneo de Anísio Teixeira, toma posse na citada Faculdade (BRANDÃO, 1993, p. 39), sendo o primeiro a lecionar a cadeira de Antropologia e Etnografia, na recém-criada Faculdade de Filosofia da Universidade da Bahia e o último representante dos antropólogos brasileiros de formação médica. Com Thales de Azevedo - a convite de Anísio Teixeira -, é firmado o convênio entre a Secretaria de Estado de Educação e Saúde da Bahia e o Departamento de Antropologia da Universidade de Columbia, em 1949, daquilo que se discutiu aqui como Projeto Columbia. 
Por tudo o que se afirmou, o Projeto Columbia tratou-se de uma iniciativa em favor da "modernização" capitalista na Bahia, nos moldes do aplicado em toda a periferia do sistema, sob o domínio do grande capital estadunidense, no padrão da modernização conservadora. Como afirmavam Lens "a América generosa não existe e nunca existiu" (2006, p. 21), e Calvin Coolidge, em 1925, “o negócio da América [referindo-se aos EUA] são os negócios" (apud LENS, 2006, p. 409). E Calvin não era qualquer um, mas o 30 presidente dos EUA (1923-1929). No mesmo sentido diria o subsecretário de Estado estadunidense, Dean Acheson, em 1944, ao definir os propósitos de seu país na Segunda Guerra Mundial: "Meu argumento é que não podemos ter pleno emprego e prosperidade nos Estados Unidos sem os mercados externos" (apud LENS, 2006, p. 502).

Sem sombra de dúvidas, o Projeto Columbia buscou entender a Bahia, sua dinâmica e potenciais possibilidades industrializadoras a partir de estudos socioantropológicos, o que facilitaria o trânsito de sua inserção no processo de acumulação internacional de capitais nos padrões da modernização conservadora, ou seja, associada aos setores mais conservadores e reacionários da sociedade. Nesse contexto, o projeto do educador liberal Anísio Teixeira, sua Escola Nova e sua noção de desenvolvimento nacional não foram libertadores da educação pública baiana, também se tornaram preciosas contribuições no mesmo sentido.

\section{Referências}

BASTIDE, Roger. Brasil terra de contrastes. $2^{\mathrm{a}}$ Edição. Coleção Corpo e Alma do Brasil. São Paulo: Difusão Européia do Livro, 1964.

BRANDÃO, Maria de Azevedo. Thales de Azevedo: dados de uma assinatura. Salvador, Associação Brasileira de Antropologia \& Universidade da Bahia, 1993.

BUENO, Ricardo (coord.). O abc do entreguismo no Brasil. Petrópolis: Vozes, 1980.

CANDIDO, Antônio. O significado de "Raízes do Brasil". In: HOLANDA, Sérgio Buarque de. Raízes do Brasil. São Paulo: Companhia das Letras, 1995.

CANCELLI, Elizabeth. Caminhos de um mal-estar de civilização: reflexões intelectuais norteamericanas para pensar a democracia e o negro no Brasil. In: Revista Espaço Acadêmico, n. 108, Maio/2010. Disponível em: http://periodicos.uem.br/ojs/index.php/EspacoAcademico/article/viewFile/10092/5602. Acessado em 27/06/2011.

CONSORTE, Josildeth Gomes. Culturalismo e educação nos anos 50: O desafio da diversidade. Cad. CEDES vol. 18 n. 43 Campinas Dec. 1997. Disponível em: http://www.scielo.br/scielo.php?script=sci_arttext\&pid=S0101-32621997000200003. Acesso em: 26/05/2010.

EMMANUEL, Arghiri et. al. Imperialismo e comércio internacional: a troca desigual. São Paulo: Global, 1981.

FREITAS, Marcos Cezar de. Educação brasileira: dilemas republicanos nas entrelinhas de seus manifestos. In: STEPHANOU, Maria \& BASTOS, Maria Helena Câmara (Orgs.). 
História e Memória da Educação no Brasil, Vol. III - Século XX. $3^{\text {a }}$ Ed. Petrópolis: Vozes, 2009.

FIGUEIREDO, Regina Érika Domingos de. História de uma Antropologia da "Boa Vizinhança": Um estudo sobre o papel dos antropólogos nos programas interamericanos de assistência técnica e saúde no Brasil e no México (1942-1960). Campinas, 2009.

HARRIS, M. Town \& Country in Brazil: a sócio-anthropological study of a small Brazilian town. New York, EUA: The Norton Library, 1956.

HAYEK, Friedrich A. O caminho da servidão. Rio de Janeiro: Livraria O Globo, 1946.

HENRIQUES, Affonso. Ascensão e queda de Getúlio Vargas (Vargas e o Estado Novo). Rio de Janeiro-São Paulo: Record, 1966.

HILTON, Stanley E. A Guerra civil brasileira: história da Revolução Constitucionalista de 1932. Rio de Janeiro: Nova Fronteira, 1982.

LENS, Sidney. A fabricação do império americano - da Revolução ao Vietnã: uma história do imperialismo dos Estados Unidos. Rio de Janeiro: Civilização Brasileira, 2006.

LUKÁCS, George. História e consciência de classe: estudos sobre a dialética marxista. São Paulo: Martins Fontes, 2003.

MAIO, Marcos Chor. A História do Projeto UNESCO: Estudos Raciais e Ciências Sociais no Brasil. Tese de doutorado apresentada ao Instituto Universitário de Pesquisas do Rio de Janeiro, 1997.

O projeto Unesco e a agenda das ciências sociais no Brasil dos anos 40 e 50. Rev. bras. Ci. Soc. vol.14 n.41, São Paulo, Out. 1999. Disponível em: http://www.scielo.br/scielo.php?pid=S0102-690919990003 00009\&script=sci_arttext.

Acesso em: 26/05/2010.

MARANHÃO, Tiago Jorge F. de Albuquerque. Apolo versus Dionísio no campo da História: o futebol em Gilberto Freyre. In: Efdeportes.com - Revista Digital, Buenos Aires, n. 73 - Jun. 2004.

MEDEIROS, Ruy. O Programa de Pesquisas Sociais Estado da Bahia-Universidade de Columbia: O seu contexto. Quaestio, Sorocaba, v. 11, n. 1, p. 89-110, maio 2009.

MOORE JR, B. As origens sociais da ditadura e da democracia: senhores e camponeses na construção do mundo moderno. São Paulo: Martins Fontes, 1975.

RIBEIRO, Maria Alice Rosa. O ensino industrial: memória e história. In: STEPHANOU, Maria \& BASTOS, Maria Helena Câmara (Orgs.). História e Memória da Educação no Brasil, Vol. III - Século XX. $3^{\text {a }}$ Ed. Petrópolis: Vozes, 2009.

SANSONE, Livio. Desigualdades duráveis, relações raciais e modernidades no Recôncavo: o caso de São Francisco do Conde. REVISTA USP, São Paulo, n.68, p. 234- 
251, dezembro/fevereiro 2005-2006. Disponível em: http://www.usp.br/revistausp/68/18livio-sansone.pdf. Acessado em 13.02.2013.

SVERSUTI, Roberto Revelino \& ALMEIDA, José Rubens Mascarenhas de. O Projeto Columbia: uma ação imperialista? In: Anais do IX Colóquio Nacional e II Internacional do Museu Pedagógico: "Desafios epistemológicos das ciências na atualidade". Universidade Estadual do Sudoeste da Bahia, Outubro de 2011. (ISSN: 2175-5493).

VICTOR, Mário. A batalha do petróleo brasileiro. $2^{\text {a }}$ Edição. Rio de Janeiro: Civilização Brasileira, 1991.

WAGLEY, Charles; AZEVEDO, Thales \& COSTA PINTO, Luiz A. Uma pesquisa sobre a vida social no Estado da Bahia: Salvador: Museu do Estado, 1950.

\section{Notas}

${ }^{1}$ Docente da Universidade Estadual do Sudoeste da Bahia; doutor em Ciências Sociais pela Pontifícia Universidade Católica de São Paulo (PUCSP); coordenador do Grupo de Estudos de Ideologia e Lutas de Classes/Museu Pedagógico/UESB; Pesquisador do Núcleo de Estudos de Ideologia e Lutas Sociais (NEILS/PUCSP).

${ }^{2}$ Categoria central da dialética marxista que entende que a realidade objetiva é um todo coerente em que cada elemento está, de uma ou outra maneira, em relação com cada elemento e, que essas relações formam, na própria realidade objetiva, correlações concretas, conjuntos, unidades ligadas entre si de maneiras completamente diversas, mas sempre determinadas (LUKÁCS, 2003).

${ }^{3}$ O Projeto Columbia University constituiu-se num convênio celebrado entre a Fundação para o Desenvolvimento da Ciência no Estado da Bahia (através do Programa de Pesquisas Sociais Estado da Bahia) e a Universidade de Columbia (EUA), envolvendo cientistas sociais brasileiros e estadunidenses. No Convênio, o Programa responsabilizou-se pela realização de pesquisas e produção de estudos sobre várias comunidades baianas, então consideradas representativas: Alto Sertão, Rio de Contas, Recôncavo, zona de transição Recôncavo e Região Cacaueira.

4 A Doutrina Monroe (1823) constitui-se no conjunto das políticas aplicadas pelo presidente dos EUA, James Monroe (1817-1825), em oposição à recolonização americana por parte de suas ex-metrópoles. Seu lema era "a América para os americanos”. Na prática, essa doutrina atribuía aos EUA o direito de polícia da América em função dos seus próprios interesses.

${ }^{5}$ No dia 11 de junho de 1940, Getúlio Vargas, a bordo do encouraçado Minas Gerais, na presença do alto escalão das Forças Armadas do Brasil, fez um discurso-bomba cujo conteúdo aludia à sua simpatia e favorecimento ao nazifascismo. Acerca, ver Henriques (1966, p. 286-7).

${ }^{6}$ Dois grupos de potências protagonizaram o cenário da Segunda Guerra Mundial: o Eixo (assim denominado por referir-se ao eixo Roma-Berlim-Tóquio, liderado por Alemanha, Japão e Itália); e os Aliados (liderado por URSS, Estados Unidos e Império Britânico). Além dessas grandes nações, outras menores compunham cada grupo. O Brasil foi o único país da América Latina a enviar tropas para os campos de batalha europeus.

${ }^{7}$ Esta usina começou a funcionar, efetivamente, em 1946, no governo de Eurico Gaspar Dutra.

${ }^{8}$ Á época, no Brasil, falava-se de possibilidades de desenvolvimento e processamento internos de combustíveis (em início dos anos 1950, estourava veemente a campanha "o petróleo é nosso").

${ }^{9}$ Publicado originalmente em 1943, teve sua edição brasileira em 1946.

${ }^{10}$ Projeto iniciado por volta de 1949, quando o Secretário da Educação e Saúde da Bahia, Anísio Teixeira convidou Charles Wagley, antropólogo da Colúmbia University - New York e este com a cooperação de Eduardo Galvão, etnólogo do Museu Nacional do Rio de Janeiro, preparou um anteprojeto de plano para estudos de comunidade em áreas rurais do Estado da Bahia. Tal projeto visava adquirir conhecimento da sociedade e da cultura dos habitantes da região rural da Bahia e uma compreensão da dinâmica de mudanças de cultura que se verificava e que se podiam esperar nesta ampla área do Brasil (WAGLEY, 1950). 
${ }^{11}$ A Refinaria de Mataripe, localizada em São Francisco do Conde, foi criada em meados de 1950, conforme Victor (1991, p. 280).

12 Sociólogo da Faculdade de Filosofia da Universidade de São Paulo. Passou 17 anos (1937-1954) no Brasil, estudando literatura, folclore e, principalmente, as relações de raça. Publicou "Brasil: terra de contrastes" (BASTIDE, 1964).

${ }^{13}$ São Paulo, por exemplo, desde 1884 já registrava a existência de fábricas (fiação de algodão e lã, de fósforo, fundições, 52 indústrias eram movidas a energia mecânica...); em 1910, mais de trinta importadores investiam na manufatura; a partir de 1915, expandem-se as indústrias já instaladas antes da I Guerra; em 1917, São Paulo já exibia sua I Exposição Industrial; em 1919, foi criado o Centro de Fiação e Tecelagem de São Paulo; no ano seguinte, já se contabilizava a fabricação de bens de consumo a alimentos; em 1924, inaugurava-se a primeira indústria de cimento brasileira; em 1928, era criado o Centro das Indústrias do Estado de São Paulo (CIESP). Fonte: Isto é Senhor Especial: São Paulo - 110 anos de industrialização. Vários autores, s.d..

14 Em 1923, a Inglaterra investiu, só no Brasil, 110 milhões de libras esterlinas, sinal da prosperidade das subsidiárias das grandes empresas estrangeiras no país.

15 Comissão de Direitos Humanos da USP. O que é a UNESCO? Disponível em: http://www.direitoshumanos.usp.br/index.php/UNESCO-Organiza\%C3\%A7\%C3\%A3o-das-Na\%C3\%A7\%C3\%B5 es-Unidas-para-a-Educa\%C3\%A7\%C3\%A3o-Ci\%C3\%AAncia-e-Cultura/o-que-e-unesco.html. Acessado em: 26/05/2010.

${ }^{16}$ Denúncias de 1949 no Brasil davam conta de envolvimento do capital nativo com o estrangeiro. Uma delas trata do relatório da "Missão Abbink", que estabelecia as normas da relação interpaíses durante os governos de Harry Truman (1945-53) e Eurico Gaspar Dutra (1946-51). Acerca ver: "Dutra abre os braços para o capital colonizador: Entendimento entre Dutra e Truman”. Jornal O Momento, 27/05/1949.

17 Dwight D. Einsenhower. Disponível em: http://www.c250.columbia.edu/c250_celebrates/ remarkable_columbians/dwight_d_eisenhower.html. Acessado em: 25/06/2010.

18 Continuidade das políticas de intercâmbio cultural visando aperfeiçoamento técnico "para o progresso da medicina nos países sul-americanos". E já se falava em "instituições latinas-norteamericanas (sic)". In: "Vai estudar nos Estados Unidos: contemplado com uma bolsa o médico baiano”. Jornal A Tarde, 29/07/1949, pg. 03. Por outro lado, "Vinte e seis estudantes superiores norte-americanos receberam bolsas de estudo do governo dos EUA para que possam estudar em 10 países latino-americanos, no próximo ano acadêmico que dentre em breve será iniciado. As bolsas de estudos foram autorizadas pelo Congresso dos EUA de acordo com uma convenção que visa estimular as relações culturais interamericanas. Os estudantes escolhidos vêm de 11 estados e do Instituto de Columbia e estudarão no Brasil, Argentina, Chile, Colômbia, Costa Rica, Cuba, República Dominicana, México, Peru e Uruguai". In: "Estudantes norte americanos estudarão na América Latina”. Jornal A Tarde, 10/08/1949, pg. 10). Arquivos Museu Pedagógico/UESB.

19 Constante do Acervo da professora Maria Brandão, filha de Thales de Azevedo e do Acervo do Museu Pedagógico/UESB.

${ }^{20}$ Figueiredo (2009) afirma que os antropólogos Franz Boas e Ralf Linton (1893-1953) empreenderam esforços, intermediados pela diretora do Museu Nacional do Rio de Janeiro, Heloísa Alberto Torres, para o envio de estudiosos da área ao Brasil, para o que contava com o apoio e influência da Fundação Rockfeller. Assim, trouxeram para o Brasil, além de Charles Wagley - pós-graduado da Universidade Columbia -, mais dois grupos de antropólogos que incluíam Ruth Lands, Buell Quan, William Lipking, James e Virgínia Watson, Yolanda e Robert Murphy. O esforço da Fundação Rockfeller é bem sintomático nesse intercâmbio entre os cientistas dos dois países. Aliás, vale ressaltar que tudo se fez através do recém-criado Instituto para Assuntos Interamericanos (IAIA), dirigido por Nelson Rockfeller. Com o mesmo intuito, foi criada a Smithsoniam Instituition/SI, comprometida em organizar e disponibilizar as informações estratégicas.

Recebido em nov/2013

Aprovado em nov/2013 